\title{
Influence of the Polymer Glass Transition Temperature and Molecular Weight on Drug Amorphization Kinetics Using Ball Milling
}

\author{
Camilla Asgreen ${ }^{1,2}$, Matthias Manne Knopp ${ }^{3}$, Jeppe Skytte ${ }^{2}$ and Korbinian Löbmann ${ }^{1, *(1)}$ \\ 1 Department of Pharmacy, University of Copenhagen, DK-2100 Copenhagen, Denmark; \\ camilla.asgreen@sund.ku.dk \\ 2 Pharmacosmos A/S, DK-4300 Holbaek, Denmark; jeppe.skytte@gmail.com \\ 3 Bioneer:FARMA, Department of Pharmacy, University of Copenhagen, DK-2100 Copenhagen, Denmark; \\ matthias.manne.knopp@sund.ku.dk \\ * Correspondence: korbinian.loebmann@sund.ku.dk
}

Received: 30 March 2020; Accepted: 25 May 2020; Published: 27 May 2020

\begin{abstract}
In this study, the putative correlation between the molecular mobility of a polymer and the ball milling drug amorphization kinetics (i.e., time to reach full drug amorphization, $t_{\mathrm{a}}$ ) was studied using different grades of dextran (Dex) and polyvinylpyrrolidone (PVP) and the two model drugs indomethacin (IND) and chloramphenicol (CAP). In general, IND had lower $t_{\mathrm{a}}$ values than CAP, indicating that IND amorphized faster than CAP in the presence of the polymers. In addition, an increase in polymer molecular weight $\left(\mathrm{M}_{\mathrm{W}}\right)$ also led to an increase in $t_{\mathrm{a}}$ for all systems investigated up to a critical $\mathrm{M}_{\mathrm{W}}$ for each polymer, which was in line with an increase of the glass transition temperature $\left(\mathrm{T}_{\mathrm{g}}\right)$ up to the critical $\mathrm{M}_{\mathrm{W}}$ of each polymer. Hence, the increase in $t_{\mathrm{a}}$ seemed to correlate well with the $T_{g} / M_{w}$ of the polymers, which indicates that the polymers' molecular mobility had an influence on the drug amorphization kinetics during ball milling.
\end{abstract}

Keywords: amorphous; solid dispersion; ball-milling; milling time; amorphization kinetics

\section{Introduction}

The use of the amorphous form is one of the most promising approaches to overcoming the solubility challenge presented by the increasing amount of poorly soluble drugs [1-3]. Since amorphous solids are disordered and thus in a higher energy state compared to their crystalline counterparts [1], they are thermodynamically unstable and tend to crystallize during storage. Hence, stabilization of the amorphous form, especially through incorporation in a polymeric carrier to create a so-called amorphous solid dispersion (ASD), have been widely investigated [3]. Since the drug itself may be miscible or even soluble in the polymer, such an ASD can in theory be thermodynamically stable if the drug loading is below its equilibrium solubility in the polymer at the storage conditions [4]. In contrast, drug loadings above the equilibrium solubility will eventually lead to the crystallization of the drug [5]. For these thermodynamically unstable systems, other factors that contribute to the stabilization of the amorphous drug in an ASD become more relevant, such as potential intermolecular interactions between the drug and polymer [6], or a decrease in molecular mobility [7].

In this regard, it has been shown that increasing the polymer chain length/molecular weight $\left(M_{W}\right)$ increases the physical stability of an ASD of indomethacin (IND) in polyvinylpyrrolidone (PVP) as a result of overall reduced molecular mobility [8]. Furthermore, the $\mathrm{M}_{\mathrm{w}}$ of the polymer has also been shown to affect the dissolution rate and performance of the drug from an ASD. Here, increasing the $\mathrm{M}_{\mathrm{w}}$ of PVP decreased the dissolution rate of celecoxib compared to PVP with lower $\mathrm{M}_{\mathrm{w}}$ [9]. Nevertheless, the ASDs with the lower $\mathrm{M}_{\mathrm{w}}$ PVP did not display the best overall dissolution performance (area under 
the dissolution-time curve) due to an inferior precipitation-inhibiting effect compared to the ASDs containing higher $\mathrm{M}_{\mathrm{w}}$ PVP.

In order to incorporate the drug into the polymer network, several methods are described in the literature, including ball milling, quench cooling and spray drying. Ball milling is often used in early-stage research as it can be performed at a small scale and does not require any heat or solvents [10]. On the other hand, the method requires a milling time long enough for the incorporation of the drug into the polymer network to achieve full amorphization, which may be as long as $2 \mathrm{~h}$ when using an oscillatory ball mill or even $8 \mathrm{~h}$ when using a planetary mill $[10,11]$. However, little is known about the influence of polymer $\mathrm{M}_{\mathrm{w}}$ on the ball-milling time required to reach full drug amorphization $\left(t_{\mathrm{a}}\right)$. In this study, it is hypothesized that the incorporation of a drug into the polymer is dependent on the molecular mobility of the polymer. Hence, polymers with higher $\mathrm{M}_{\mathrm{w}}$ may require longer milling times to obtain an ASD during milling. In this regard, it has been shown that the relationship between the increasing glass-transition temperature $\left(\mathrm{T}_{\mathrm{g}}\right)$ and the increasing $\mathrm{M}_{\mathrm{W}}$ of a polymer only applies up to a critical $M_{w}$, above which the $T_{g}$ does not increase further $[12,13]$. Since the $T_{g} / M_{w}$ of a polymer is also indirectly a measure of the molecular mobility of the polymer, this study aims to investigate the putative correlation between the molecular mobility $\left(\mathrm{T}_{\mathrm{g}} / \mathrm{M}_{\mathrm{w}}\right)$ of a polymer and the ball-milling amorphization kinetics $\left(t_{\mathrm{a}}\right)$ of different grades of dextran and PVP, and the two model drugs IND and chloramphenicol (CAP).

\section{Materials and Methods}

\subsection{Materials}

Dextrans of different $\mathrm{M}_{\mathrm{w}}(\mathrm{kDa})$ (Dex 1, Dex 1.5, Dex 3.5, Dex 5, Dex 10, Dex 12, Dex 40, Dex 70 and Dex 500) were kindly supplied by Pharmacosmos A/S (Holbaek, Denmark), and PVPs of different $\mathrm{M}_{\mathrm{W}}$ (K12, K17, K30 and K90) were kindly supplied by BASF (Ludwigshafen, Germany). PVP K60 and chloramphenicol (CAP) were sourced from Sigma Aldrich (St. Louis, MO, USA) and indomethacin (IND) was sourced from Fagron (Copenhagen, Denmark).

\subsection{Differential Scanning Calorimetry}

To determine the $\mathrm{T}_{\mathrm{g}}$ of the different grades of PVP, a Discovery differential scanning calorimeter (DSC) from TA Instruments Inc. (New Castle, DE, USA) was used. Samples (2-4 mg) were analysed in TA Instruments Tzero aluminium hermetic pans with a perforated lid under $50 \mathrm{~mL} / \mathrm{min}$ nitrogen gas flow using modulated temperature DSC (mDSC). The samples were heated from $5-200{ }^{\circ} \mathrm{C}$ using a heating rate of $2{ }^{\circ} \mathrm{C} / \mathrm{min}$ with a modulation amplitude of $0.212{ }^{\circ} \mathrm{C}$ over a period of $40 \mathrm{~s}$. The $\mathrm{T}_{\mathrm{g}}$ (midpoint) was determined using the TA Instruments TRIOS software (version 4.1.1).

\subsection{Ball Milling}

The time to reach full drug amorphization $\left(t_{\mathrm{a}}\right)$ was studied using an oscillatory ball mill (Mixer mill MM400, Retsch GmbH \& Co., Haan, Germany), which was placed in a cold room $\left(5^{\circ} \mathrm{C}\right)$. Physical mixtures of drug and polymer (1000 mg) were placed in $25 \mathrm{~mL}$ jars containing two $12 \mathrm{~mm}$ stainless steel ball bearings (Retsch GmbH \& Co., Haan, Germany) and milled at a frequency of $30 \mathrm{~Hz}$. The investigated drug-polymer ratios were 10:90 w/w and 50:50 w/w for mixtures containing dextrans and PVP, respectively. In order to obtain homogeneous mixtures, the drug-polymer powder mixtures were mixed without the ball bearings for $5 \mathrm{~min}(0 \mathrm{~min}$ sample). Subsequently, the ball bearings were added to the jars and samples of approximately $10 \mathrm{mg}$ were collected at predetermined time points, from 0-60 min. Furthermore, both IND and CAP were milled without polymer to evaluate their amorphization kinetics against the drug-polymer mixtures. 


\subsection{X-Ray Powder Diffraction}

The samples collected from ball milling were analysed using X-ray powder diffractometry (XRPD) with an X'Pert Pro diffractometer from PANalytical (Almelo, the Netherlands) in order to evaluate whether they were $X$-ray amorphous. The diffractometer operated in reflection mode with the use of $\mathrm{CuK} \alpha$ radiation $(1.54187 \AA$ ), with the acceleration voltage and current set to $45 \mathrm{kV}$ and $40 \mathrm{~mA}$, respectively. Samples were scanned from 5 to $30^{\circ} 2 \theta$ on aluminum sample holders with a scan speed of $0.067^{\circ} 2 \theta / \mathrm{s}$ and a step size of $0.026^{\circ}$. Results were analyzed using the $X^{\prime}$ Pert Data Viewer software (version 1.2, PANalytical, Almelo, the Netherlands). The amorphousness of the samples in this study was investigated solely using XRPD, which does not provide information on the homogeneity of the sample, i.e., whether a homogeneous single-phase amorphous solid dispersion has been created after the applied $t_{\mathrm{a}}$. Hence, the time $t_{\mathrm{a}}$ refers to the samples being $\mathrm{X}$-ray amorphous.

\section{Results}

It has previously been shown that the $T_{g}$ of dextrans increases with increasing $M_{w}$ up to around $40 \mathrm{kDa}$, after which a further increase in $\mathrm{M}_{\mathrm{W}}$ did not result in a significant further increase in the $\mathrm{T}_{\mathrm{g}}$ [13]. Similarly, the $\mathrm{T}_{\mathrm{g}}$ of PVP only increased with increasing $\mathrm{M}_{\mathrm{w}}$ up to around $360 \mathrm{kDa}$ (see Table 1 and Figure 1).

Table 1. The polymer molecular weight $\left(\mathrm{M}_{\mathrm{w}}\right)$ and corresponding glass-transition temperature $\left(\mathrm{T}_{\mathrm{g}}\right)$ for dextrans (Dex) and polyvinylpyrrolidone (PVP) and their influence on the ball milling time to reach full drug amorphization $\left(t_{a}\right)$ for both chloramphenicol (CAP) and indomethacin (IND).

\begin{tabular}{ccccc}
\hline \multirow{2}{*}{ Compound } & \multirow{2}{*}{$\mathbf{M}_{\mathbf{w}}(\mathbf{k D a})$} & \multirow{2}{*}{$\mathbf{T}_{\mathbf{g}}\left({ }^{\circ} \mathbf{C}\right)$} & \multicolumn{2}{c}{$\boldsymbol{t}_{\mathbf{a}}(\mathbf{m i n})$} \\
\cline { 4 - 5 } & & & $\mathbf{C A P}$ & $\mathbf{I N D}$ \\
\hline Dex 1 & $1.0^{\mathrm{a}}$ & $151.8 \pm 0.2^{\mathrm{c}}$ & 10.0 & 7.5 \\
Dex 1.5 & $1.6^{\mathrm{a}}$ & $162.4 \pm 1.1^{\mathrm{c}}$ & 15.0 & 10.0 \\
Dex 3.5 & $3.7^{\mathrm{a}}$ & $194.8 \pm 0.4^{\mathrm{c}}$ & 22.5 & 15.0 \\
Dex 5 & $5.2^{\mathrm{a}}$ & $204.4 \pm 0.8^{\mathrm{c}}$ & 22.5 & 20.0 \\
Dex 10 & $9.6^{\mathrm{a}}$ & $212.8 \pm 0.9^{\mathrm{c}}$ & 30.0 & 25.0 \\
Dex 12 & $11.6^{\mathrm{a}}$ & $216.9 \pm 0.3^{\mathrm{c}}$ & 30.0 & 30.0 \\
Dex 40 & $39.6^{\mathrm{a}}$ & $223.2 \pm 0.0^{\mathrm{c}}$ & 45.0 & 45.0 \\
Dex 70 & $64.6^{\mathrm{a}}$ & $224.0 \pm 0.6^{\mathrm{c}}$ & 52.5 & 45.0 \\
Dex 500 & $544.3^{\mathrm{a}}$ & $225.8 \pm 0.8^{\mathrm{c}}$ & 60.0 & 45.0 \\
PVP K12 & $2.5^{\mathrm{b}}$ & $104.8 \pm 0.9$ & 20.0 & 15.0 \\
PVP K17 & $9.0^{\mathrm{b}}$ & $142.1 \pm 0.7$ & 20.0 & 15.0 \\
PVP K30 & $49^{\mathrm{b}}$ & $162.5 \pm 0.2$ & 25.0 & 17.5 \\
PVP K60 & $360^{\mathrm{b}}$ & $178.9 \pm 0.6$ & 35.0 & 22.5 \\
PVP K90 & $1250^{\mathrm{b}}$ & $178.5 \pm 0.2$ & 45.0 & 25.0 \\
\hline
\end{tabular}

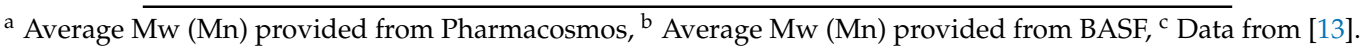

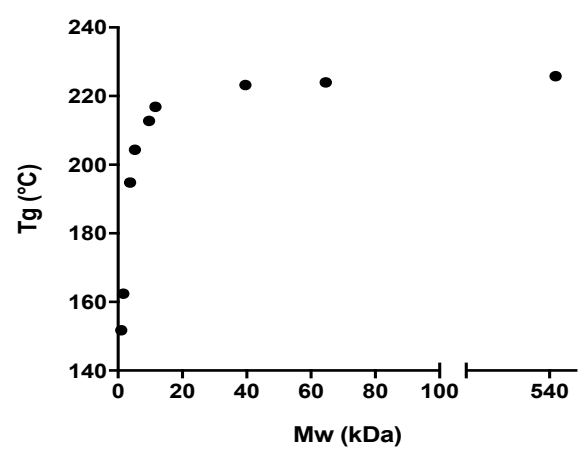

(a)

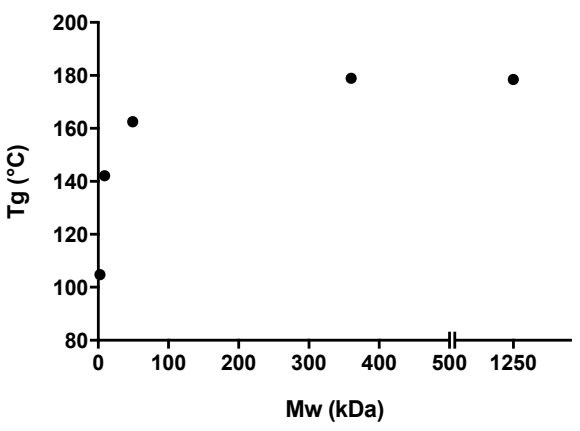

(b)

Figure 1. Correlation between the $\mathrm{T}_{\mathrm{g}}\left({ }^{\circ} \mathrm{C}\right)$ and the $\mathrm{M}_{\mathrm{W}}(\mathrm{kDa})$ for (a) different dextran grades and (b) different PVP grades. The $\mathrm{T}_{\mathrm{g}}$ values for the different dextran grades were obtained from [13]. 
The pure drugs were milled in order to investigate their behaviour upon milling for $60 \mathrm{~min}$. It was found that pure IND fully amorphized after $60 \mathrm{~min}$ of milling $\left(t_{\mathrm{a}}=60 \mathrm{~min}\right)$. Hence, the drug can be prepared in its amorphous form without a carrier. On the other hand, pure CAP does not fully amorphize even after $60 \mathrm{~min}$ of milling, which was evident in the remaining crystalline diffractions in the XRPD diffractograms (data not shown). CAP is therefore not able to amorphize on its own under these conditions.

The amorphization kinetics upon milling were investigated for the different drug-polymer systems. The $t_{\mathrm{a}}$ was characterized as the first time point where no Bragg peaks were visible in the XRPD diffractograms. Table 1 summarizes the $t_{\mathrm{a}}$ values for the different systems, and two representative examples for the amorphization kinetics are shown in Figure 2. Figure 2a illustrates that IND fully amorphized in the presence of Dex 40 after $45 \mathrm{~min}$ of milling, as indicated by the lack of Bragg peaks in the diffractogram. Figure $2 \mathrm{~b}$ illustrates that it was also possible to obtain an ASD containing CAP and PVP K60 with a $t_{\mathrm{a}}$ of $35 \mathrm{~min}$.

For a better visualization, the obtained $t_{\mathrm{a}}$ values presented in Table 1 are illustrated in Figures 3 and 4 for the various grades of dextrans and PVP, respectively. In general, IND had lower $t_{\mathrm{a}}$ values than CAP, indicating that IND amorphized faster than CAP in the presence of the polymers. This is in line with the findings from the milling of the pure drugs, where IND could be amorphized on its own. In addition, an increase in polymer $\mathrm{M}_{\mathrm{w}}$ also led to an increase in $t_{\mathrm{a}}$. The fastest amorphization kinetics were obtained for Dex 1 and PVP K12 (i.e., the polymers with the lowest $M_{W}$ ). With the increasing $M_{W}$ of the polymers, the subsequent increase in $t_{\mathrm{a}}$ is most pronounced for dextrans grades below $40 \mathrm{kDa}$ (Dex 40) and PVP grades below $360 \mathrm{kDa}$ (PVP K60). Furthermore, the presence of the polymers allowed CAP to become amorphous and reduced the $t_{\mathrm{a}}$ of IND compared to milling the drugs on their own.

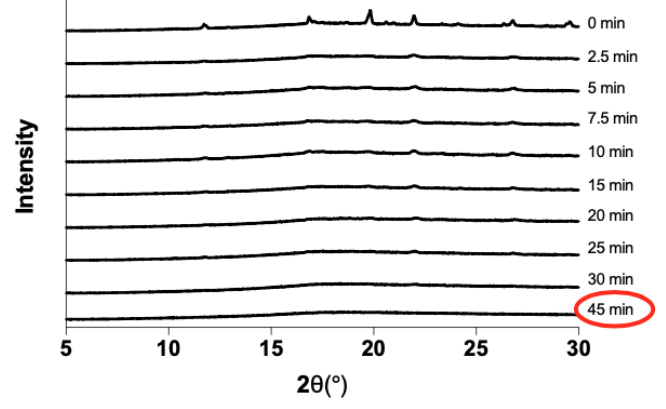

IND:Dex 40 (10:90) (a)

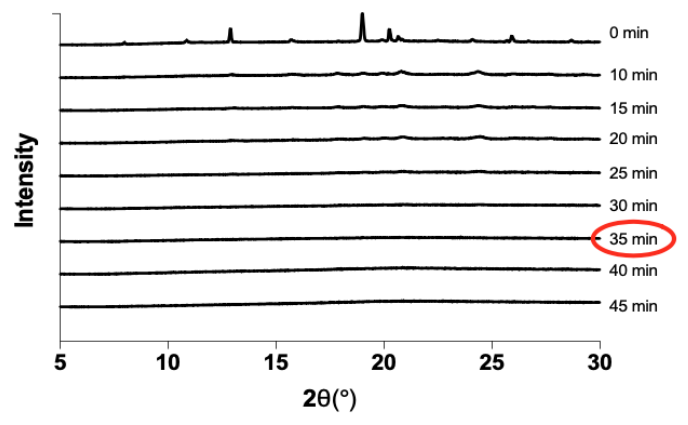

CAP:PVP K60 (50:50) (b)

Figure 2. X-ray powder diffractometry (XRPD) diffractograms showing the decrease in crystallinity over time for a mixture of IND and Dex $40(10: 90 w / w)(\mathbf{a})$ and a mixture of CAP and PVP K60 (50:50 $w / w)(\mathbf{b})$. The $t_{\mathrm{a}}$ is marked with a red circle.

When comparing Figure 1 with Figures 3 and 4 , it can be seen that an increase in $M_{W}$ affects both the $\mathrm{T}_{\mathrm{g}}$ of the polymer and the $t_{\mathrm{a}}$ in a similar fashion. Furthermore, the increase of both $t_{\mathrm{a}}$ and $\mathrm{T}_{\mathrm{g}}$ is most pronounced for lower polymer $\mathrm{M}_{\mathrm{W}}$, and less pronounced after the critical polymer $\mathrm{M}_{\mathrm{W}}$ is reached. Hence, this finding indicates that the polymer $\mathrm{M}_{\mathrm{w}}$ (i.e., molecular mobility) appears to influence the amorphization kinetics, and hence the $t_{\mathrm{a}}$. In this regard, it is important to emphasize that it has been shown that the polymer $\mathrm{M}_{\mathrm{w}}$ does not influence the equilibrium solubility of the drug in the polymer at ambient temperature [14]. On the other hand, it has been shown that an ASD comprising the drug IND together with PVP of a higher $\mathrm{M}_{\mathrm{W}}$ (K30) showed increased physical stability as a result of overall reduced molecular mobility compared to an ASD with PVP of lower $\mathrm{M}_{\mathrm{W}}$ (K12) [8]. In other words, whilst a higher $\mathrm{M}_{\mathrm{w}}$ is more efficient at preventing crystallization, it also requires longer milling times to achieve a fully amorphous solid dispersion. 


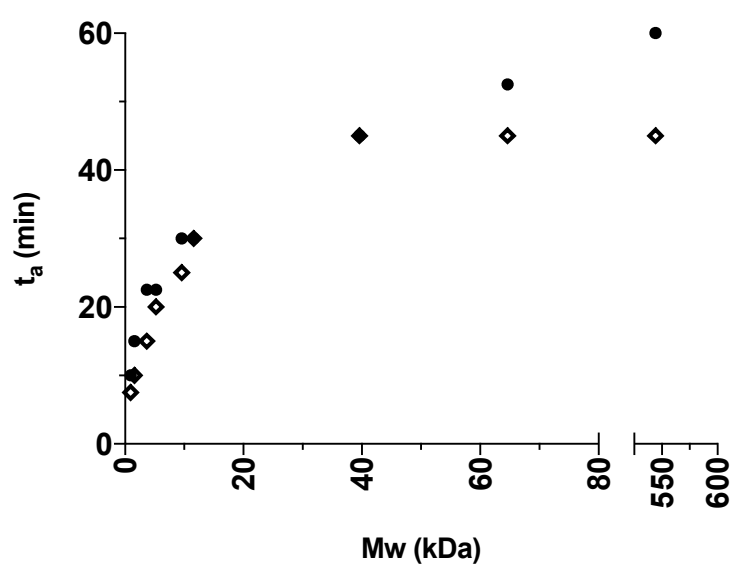

Figure 3. The $t_{\mathrm{a}}$ (min) of the different IND:Dex 10:90 w/w (diamond) and CAP:Dex 10:90 w/w (circle) mixtures plotted against the average $\mathrm{M}_{\mathrm{w}}(\mathrm{kDa})$ of the polymer grade in the certain mixture.

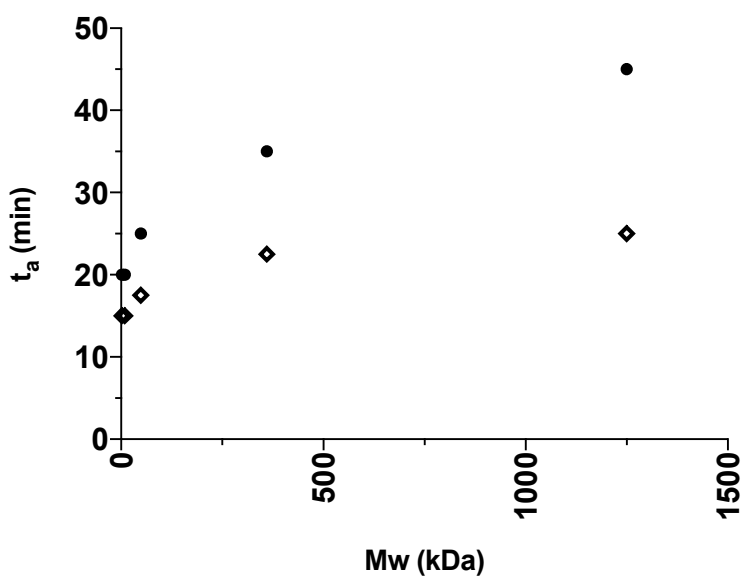

Figure 4. The $t_{\mathrm{a}}(\mathrm{min})$ of the different IND:PVP 50:50 $w / w$ (diamond) and CAP:PVP 50:50 $w / w$ (circle) mixtures plotted against the average $\mathrm{M}_{\mathrm{W}}(\mathrm{kDa})$ of the polymer grade in the certain mixture.

Finally, it should be noted that, apart from the $\mathrm{T}_{\mathrm{g}} / \mathrm{M}_{\mathrm{w}}$ of the polymer, there are potentially other factors contributing to the overall amorphization kinetics. This study showed for example that the good glass former IND showed faster amorphization kinetics than the poor glass former CAP when being milled together with a given polymer. It is also known that the polymer $\mathrm{M}_{\mathrm{w}}$ does not influence the equilibrium solubility of the drug in the polymer [14]. Nevertheless, in light of the equilibrium solubility of the drug in the polymer, it would be interesting to investigate how different drug loadings would impact the amorphization kinetics. In this context, molecular interactions between the drug and the polymer, the strength of these interactions and the final $\mathrm{T}_{\mathrm{g}}$ of the formed ASD all potentially contribute to the amorphization kinetics during milling. Lastly, the presence of water in a polymer significantly impacts its properties, as water acts as a plasticizer [15], lowering the polymer's $\mathrm{T}_{\mathrm{g}}$ and increasing its mobility, but also reducing the equilibrium solubility of the drug in the polymeric carrier [16]. Hence, given that most polymers are hygroscopic, the impact of water represents another critical parameter to be investigated in future studies.

\section{Conclusions}

In summary, this study found a correlation between the polymer $\mathrm{T}_{\mathrm{g}} / \mathrm{M}_{\mathrm{w}}$ and ball-milling amorphization kinetics. The findings support our original hypothesis that increasing polymer $\mathrm{M}_{\mathrm{W}}$ will increase the $t_{\mathrm{a}}$, probably as a consequence of decreased molecular mobility.

Author Contributions: Conceptualization and methodology, C.A., M.M.K. and K.L.; investigation, visualization and writing-original draft preparation, C.A.; supervision, writing—review and editing, M.M.K., J.S. and K.L. All authors have read and agreed to the published version of the manuscript. 
Funding: This research was partly funded by Pharmacosmos A/S.

Conflicts of Interest: Jeppe Skytte was employed at Pharmacosmos A/S during this project. Otherwise, the authors report no conflict of interest. The study was designed independent of the company.

\section{References}

1. Kawabata, Y.; Wada, K.; Nakatani, M.; Yamada, S.; Onoue, S. Formulation design for poorly water-soluble drugs based on biopharmaceutics classification system: Basic approaches and practical applications. Int. J. Pharm. 2011, 420, 1-10. [CrossRef] [PubMed]

2. Hancock, B.; Parks, M. What is the True Solubility Advantage for Amorphous Pharmaceuticals? Pharm. Res. 2000, 17, 397-404. [CrossRef] [PubMed]

3. Grohganz, H.; Priemel, P.A.; Löbmann, K.; Nielsen, L.H.; Laitinen, R.; Mullertz, A.; Van den Mooter, G.; Rades, T. Refining stability and dissolution rate of amorphous drug formulations. Expert Opin. Drug Deliv. 2014, 11, 977-989. [CrossRef] [PubMed]

4. Knopp, M.M.; Olesen, N.E.; Holm, P.; Lobmann, K.; Holm, R.; Langguth, P.; Rades, T. Evaluation of drug-polymer solubility curves through formal statistical analysis: Comparison of preparation techniques. J. Pharm. Sci. 2015, 104, 44-51. [CrossRef] [PubMed]

5. Rask, M.B.; Knopp, M.M.; Olesen, N.E.; Holm, R.; Rades, T. Comparison of two DSC-based methods to predict drug-polymer solubility. Int. J. Pharm. 2018, 540, 98-105. [CrossRef] [PubMed]

6. Taylor, L.S.; Zografi, G. Spectroscopic Characterization of Interactions Between PVP and Indomethacin in Amorphous Molecular Dispersions. Pharm. Res. 1997, 14, 1691-1698. [CrossRef] [PubMed]

7. Baghel, S.; Cathcart, H.; O’Reilly, N.J. Polymeric Amorphous Solid Dispersions: A Review of Amorphization, Crystallization, Stabilization, Solid-State Characterization, and Aqueous Solubilization of Biopharmaceutical Classification System Class II Drugs. J. Pharm. Sci. 2016, 105, 2527-2544. [CrossRef] [PubMed]

8. Mohapatra, S.; Samanta, S.; Kothari, K.; Mistry, P.; Suryanarayanan, R. Effect of Polymer Molecular Weight on the Crystallization Behavior of Indomethacin Amorphous Solid Dispersions. Cryst. Growth Des. 2017, 17, 3142-3150. [CrossRef]

9. Knopp, M.M.; Nguyen, J.H.; Becker, C.; Francke, N.M.; Jorgensen, E.B.; Holm, P.; Holm, R.; Mu, H.; Rades, T.; Langguth, P. Influence of polymer molecular weight on in vitro dissolution behavior and in vivo performance of celecoxib:PVP amorphous solid dispersions. Eur. J. Pharm. Biopharm. Off. J. Arb. Fur Pharm. Verfahr. e.V 2016, 101, 145-151. [CrossRef] [PubMed]

10. Kasten, G.; Grohganz, H.; Rades, T.; Löbmann, K. Development of a screening method for co-amorphous formulations of drugs and amino acids. Eur. J. Pharm. Sci. Off. J. Eur. Fed. Pharm. Sci. 2016, 95, 28. [CrossRef] [PubMed]

11. Mahieu, A.; Willart, J.-F.; Dudognon, E.; Danède, F.; Descamps, M. A New Protocol To Determine the Solubility of Drugs into Polymer Matrixes. Mol. Pharm. 2013, 10, 560-566. [CrossRef] [PubMed]

12. Fox, T.G.; Flory, P.J. The glass temperature and related properties of polystyrene. Influence of molecular weight. J. Polym. Sci. 1954, 14, 315-319. [CrossRef]

13. Larsen, B.S.; Skytte, J.; Svagan, A.J.; Meng-Lund, H.; Grohganz, H.; Löbmann, K. Using dextran of different molecular weights to achieve faster freeze-drying and improved storage stability of lactate dehydrogenase. Pharm. Dev. Technol. 2018, 24, 323-328. [CrossRef] [PubMed]

14. Knopp, M.M.; Olesen, N.E.; Holm, P.; Langguth, P.; Holm, R.; Rades, T. Influence of Polymer Molecular Weight on Drug-polymer Solubility: A Comparison between Experimentally Determined Solubility in PVP and Prediction Derived from Solubility in Monomer. J. Pharm. Sci. 2015, 104, 2905-2912. [CrossRef] [PubMed]

15. Lehmkemper, K.; Kyeremateng, S.O.; Heinzerling, O.; Degenhardt, M.; Sadowski, G. Impact of polymer type and relative humidity on the long-term physical stability of amorphous solid dispersions. Mol. Pharm. 2017, 14, 4374-4386. [CrossRef] [PubMed]

16. Lehmkemper, K.; Kyeremateng, S.O.; Heinzerling, O.; Degenhardt, M.; Sadowski, G. Long-term physical stability of PVP-and PVPVA-amorphous solid dispersions. Mol. Pharm. 2016, 14, 157-171. [CrossRef] [PubMed]

(C) 2020 by the authors. Licensee MDPI, Basel, Switzerland. This article is an open access article distributed under the terms and conditions of the Creative Commons Attribution (CC BY) license (http://creativecommons.org/licenses/by/4.0/). 